\title{
Closing of Shrinkage Cavities by Means of Open-Die Forging
}

\author{
Janine Hauri ${ }^{1, a^{*}}$, Marcel Graf ${ }^{2, b}$, Birgit Awiszus ${ }^{2, c}$ and Rudolf Kawalla ${ }^{3, d}$ \\ ${ }^{1}$ Hans G. Hauri KG Mineralstoffwerke, Bergstrasse 114, 79268 Boetzingen, Germany \\ ${ }^{2}$ Professorship Virtual Production Engineering, Reichenhainer Strasse 70, 09126 Chemnitz, \\ Germany \\ ${ }^{3}$ Institute of Metal Forming, Bernhard-von-Cotta-Strasse 4, 09599 Freiberg, Germany \\ aj.hauri@t-online.de, ${ }^{b}$ marcel.graf@mb.tu-chemnitz.de, ${ }^{c}$ birgit.awiszus@mb.tu-chemnitz.de, \\ rudolf.kawalla@imf.tu-freiberg.de
}

Keywords: voids, cast ingots, open-die forging, cavity closing, bulk forming, steel, pore closure

\begin{abstract}
Inner cavities in cast ingots have to be closed by means of open-die forging to guarantee the integrity of the forged components during usage. In the paper a differentiation is made between the macroscopic and the microscopic closing of natural inner cavities. Special attention is paid to the dendritic structure of the surfaces of inner cavities and their impact on the microscopic closing behavior. Additionally, investigation showed that a closing on the microscopic scale is only possible if the cavities do not come in contact to the atmosphere during hot forming. For the analysis of the cavity closing, ingots of a heat-treatable, hot-working and a cold-working steel were used. The ingots were cast, forged and the surface of the inner voids was analyzed with the help of light-microscopy, SEM and EDS for the microstructure and by using tensile tests on macroscopic scale. Also, numerical investigations were a part of the work, whereby the parameters void size, void shape and anvil-shape were varied. As a result of the numerical investigation, a so called closing function was formed. This function enables the user to calculate the necessary heightreduction for closing of inner cavities of the regarded ingot format.
\end{abstract}

\section{Introduction}

The common used semi-finished products in open-die forging of large forging products are cast ingots. Because of contraction and shrinkage processes during solidification of the melt, inner cavities with a dendritic surface build up, mainly along the center line of such ingots. As long as they are not contaminated and have had no contact to the atmosphere, it is possible to close them during open-die forging.

In former experimental studies, artificial holes were drilled into laboratory samples or small ingots (e. g. [1], [2]). The problem of such examinations lies in the fact, that firstly the surface is relatively smooth and secondly, because of the contact to the atmosphere during heating and hot forming, an oxidation of the cavity surface takes place. Thus, only the macroscopic closing process of the voids can be regarded, which is not totally comparable to the closing of an inartificial, enclosed cavity with a dendritic surface.

For numerical simulation, also only the macroscopic closing process with respect to void closure was considered in former projects. Thereby, circular (2D) or cylindrical (3D) cavities without a structured surface were analyzed (e. g. [3], [4]).

In this paper, the results of experimental and numerical simulations are presented, that take the inartificial surface structure of inner cavities and its closing behavior during open-die forging into account. Therefore, an unalloyed quality steel (steel grade 1.0503), a hot-working steel (steel grade 1.2344) and a cold-working steel (steel grade 1.2379) were investigated. Finally, a so named closing function was developed, which is also stated in this publication. 


\section{Experimental Examinations}

Casting of ingots. For the analysis of the surface structure of inner cavities, laboratory ingots $(\sim 53 \mathrm{~kg})$ were cast in a vacuum-induction-melting furnace at the Steel Institute of the TU Bergakademie Freiberg. The ingots were produced by a bottom casting process with the help of a steel mold, which contained a steel lid for a fast solidification and the formation of a stable outer shell [5]. Thus, an enclosed and scale-free inner cavity could be formed. The cast parameters were the same for all castings, so it is assumed that the structure of the cavities is comparable. Also, larger ingots were cast from an industry partner.

After the casting, a dendritic surface was detectable for all three types of steel and both ingot formats. The cavities were formed along the center line of the ingots and even with naked eye dendritic structures were visible on the surface (see Fig. 1). The dendrites grow free into the cavity during solidification and smaller voids are enclosed between the dendrite arms (see Fig. 2).

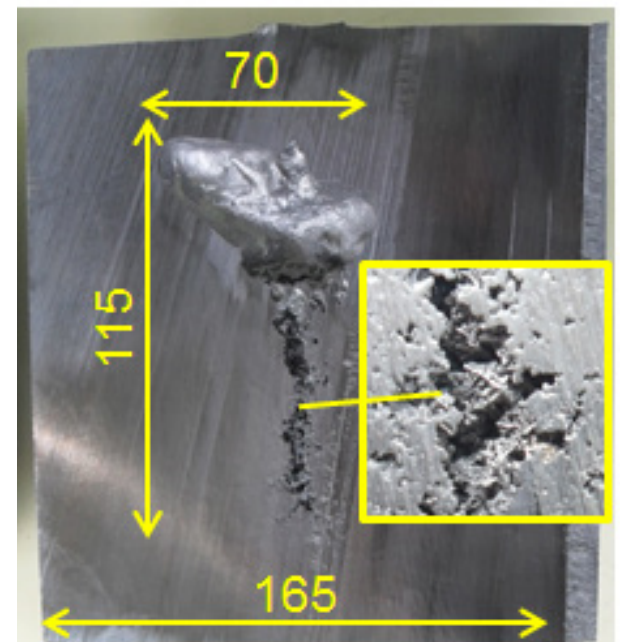

Fig. 1. Laboratory ingot with cavity

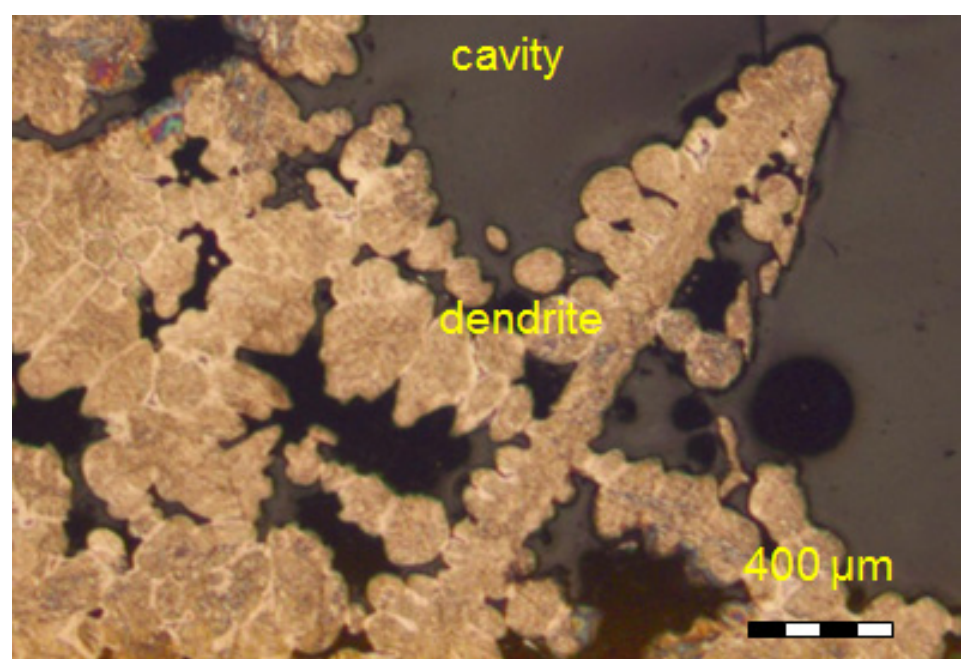

Fig. 2. Dendritic structure on cavity surface

An investigation by means of EDS was also undertaken. The results showed no significant differences in the chemical composition of the cavity surface and the base material. For that reason, the material properties can be regarded as homogeneous for the whole ingot. This means determined flow curves on base of cylindrical compression tests (samples with cast microstructure) for each of the materials can be directly implemented in a numerical simulation system.

One-Step Forging Experiments. At first, one-step forging experiments were done at the Institute of Metal Forming of the TU Bergakademie Freiberg. For these examinations, the laboratory ingots were forged with global height reductions of $12.5 \%, 30 \%$ and $50 \%$ on a $10 \mathrm{MN}$ universal forging press, whereby a tool speed of $10 \mathrm{~mm} / \mathrm{s}$ was realized [6]. The ingots were heated up to $1200^{\circ} \mathrm{C}$ in an electrical furnace and cooled down on air after hot-forming.

In Fig 3 a)-d) the successive closing of the inner cavities is depicted. Firstly, the inner cavities are reduced along the forging direction and widened vertical to it. Then, the surfaces of the former cavities lie flat on each other. From the macroscopic point of view, it may be not possible to detect a remaining cavity with naked eye anymore. But on the microscopic scale it is still visible, that the cavity is not closed totally. Also, there are no cracks as result of the forging operation. If the forging process continues, material bridges exist in the area of the former enlarged cavity surface. This gives hint, that new grains must have been formed during the forging process, most probably because of recrystallization processes with nucleation and grain growth. The volume of the remaining pores is continuously reduced and the material bridges become larger with ongoing hotworking. At this point of observation, small pore chains are detectable on the micrographs. If there are remaining pores between the triple points of dendrite arms, it seems to be difficult to close them even when using a large height-reduction, which induces at least the critical plastic strain as base for dynamic recrystallization in the contact area. 

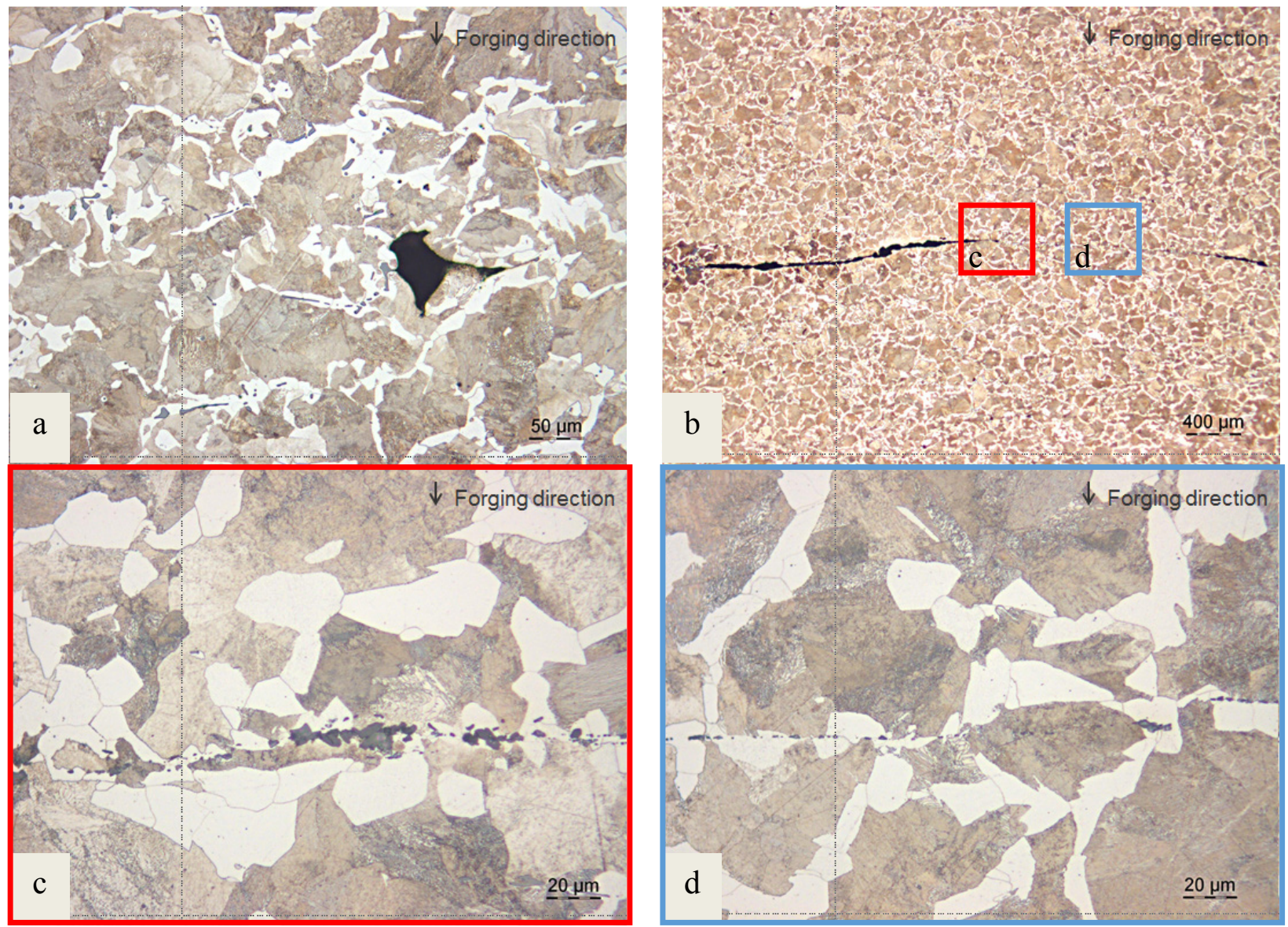

Fig. 3. Successive closing process of inner cavities for C45 (different magnifications): a) retained cavity with height reduction of $30 \%$ along forging direction b) elongation of opposite cavity surfaces with height reduction of $50 \%$ c) elongated cavity with building up of material bridges d) material bridges with remaining pore chains

Multiple-Step Forging Experiments. If a dynamical or meta-dynamical recrystallization is the reason for a building up of new grains in the area of the former cavity surface, the critical plastic strain must be exceeded. The question is, if a large height-reduction is necessary to reach that goal, or if it is possible to establish smaller height reductions.

For a comparative study one laboratory block was forged in a single step with a global diameter reduction of $50 \%$. Afterwards, a second ingot was forged in four steps, whereby every height reduction was about $20 \mathrm{~mm}$. For the first ingot, a global plastic strain $\varphi=0.663$ was caused. For the second ingot the induced global plastic strains of every single step were smaller, according to Table 1.

Table 1. Forging procedure for 1 and 4-step forming of laboratory ingot

\begin{tabular}{|c|c|c|c|c|c|}
\hline $\mathrm{d}_{\text {start }}=165 \mathrm{~mm}$ & $\begin{array}{c}\text { Forging steps } \\
{[\mathrm{mm}]}\end{array}$ & $\Delta \mathrm{h}^{\text {step }}[\%]$ & $\Delta \mathrm{h}^{\text {total }}[\%]$ & $\varphi^{\text {step }}$ & $\varphi^{\text {total }}$ \\
\hline 1-step & $165 \rightarrow 85$ & 48.4 & 48.4 & 0.663 & 0.663 \\
\hline 4-step forging & $165 \rightarrow 145$ & 12.1 & 12.1 & 0.129 & 0.129 \\
with break & $145 \rightarrow 125$ & 13.8 & 24.2 & 0.148 & 0.277 \\
time & $125 \rightarrow 105$ & 16.0 & 36.3 & 0.174 & 0.451 \\
& $105 \rightarrow 85$ & 19.0 & 48.4 & 0.211 & 0.663 \\
\hline
\end{tabular}

Both ingots where heated up to $1200{ }^{\circ} \mathrm{C}$ before forging. There was an operating time of $49 \mathrm{~s}$ between the removal from the furnace and start of the hot-forming operation. Measurements with a pyrometer showed, that the ingots cooled down about $50 \mathrm{~K}$ in this time. In case of the four-step forging experiment, a break time of $17 \mathrm{sec}$ between each of the four forging steps was realized. 
All forged ingots were examined by light-microscopy and the grain size was analyzed. Additionally, hot-tensile tests were performed to figure out, at which stress levels the former cavity surface re-opens. The tests demonstrated that neither the microstructure, nor grain size, nor the tensile tests show significant differences between the two forming strategies. It cannot be said under the considered conditions, that a large height reduction in one step is more beneficial than smaller height reductions for the closing of internal cavities in forging ingots. Maybe both technologies provide the starting of recrystallization. Hence, to underline this assumption complementary compression tests on the Gleeble HDS-V40 were undertaken.

Compression tests on the Gleeble. The cylindrical compression tests $(\varnothing 10 \mathrm{~mm} \times 18 \mathrm{~mm})$ on the Gleeble HDS-V40 were performed in the same way as the forging experiments of the laboratory ingots. As it is shown in Fig. 4, the samples were heated up to $1200^{\circ} \mathrm{C}$ and hold there for austenitization and homogenization. Afterwards, they were cooled down to the forming temperature and compressed with the same plastic strains as the ingots. Also the break time of $17 \mathrm{sec}$ was taken into account and a simultaneous cool down of $50 \mathrm{~K}$. In this manner, four samples were compressed: the first sample was only one time compressed, the second one two times and so on. After the last compression of each sample, an additional compression with the same parameters as used before ("control compression step") was done to make sure, if a totally or partially recreation proceeded in the break time [7]. For all compression tests, a constant strain rate of $0.1 \mathrm{~s}^{-1}$ was adjusted.

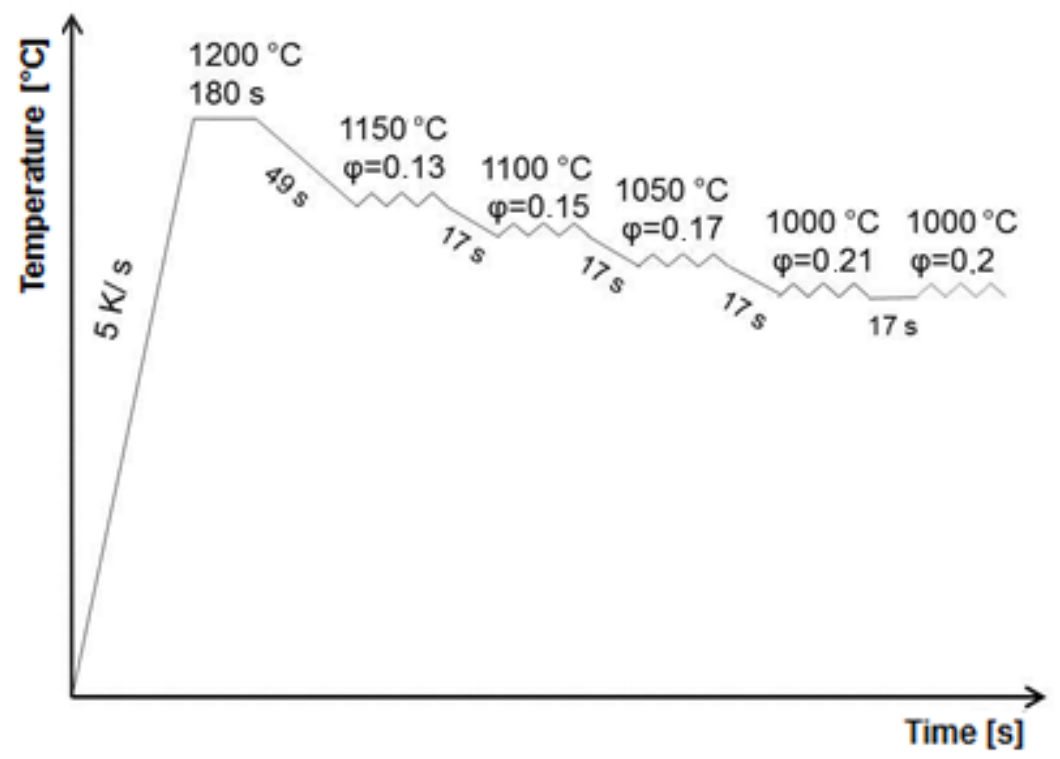

Fig. 4. Temperature-time procedure of Gleeble compression tests

As shown in Fig. 5, the initial flow stress $\sigma_{\mathrm{f} 01}$ of every "control compression step" has the same stress level as the initial flow stress before. Thus, it can be assumed, that a meta-dynamically or statically recrystallization took place in the break time.

The compression tests showed that a recrystallization with grain nucleation and grain growth is also possible if small height-reductions are used. 


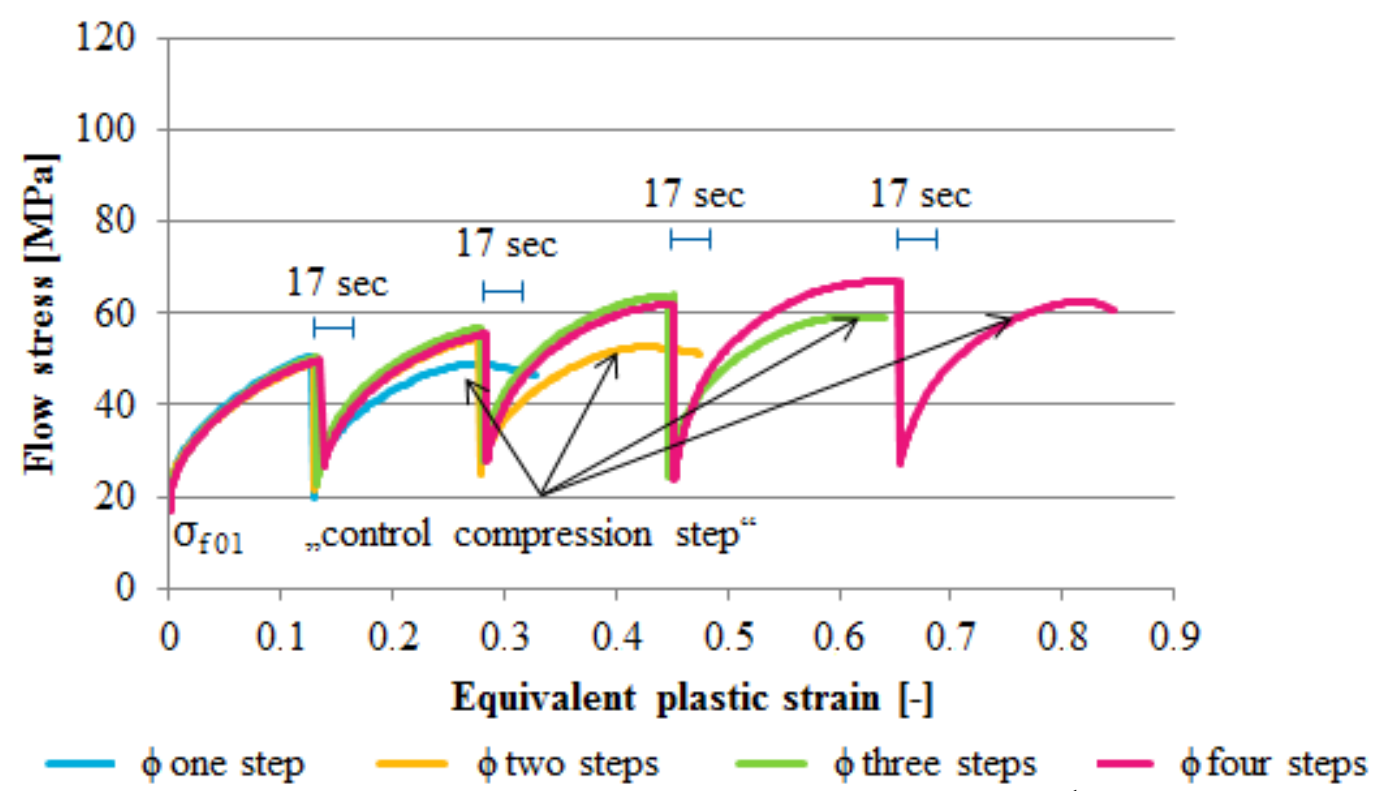

Fig. 5. Results for Gleeble compression tests with strain rate $0.1 \mathrm{~s}^{-1}$ for steel grade $\mathrm{C} 45$

Forging tests with industrial scale ingots. The results of the forging tests on laboratory ingots were used to undertake investigation on ingots on industrial scale. For the forging operations, single steps with different height reductions along the longitudinal axis of the ingots were performed. This approach is an efficient and cost-effective way to forge one ingot with different depths of penetration. In Fig. 6 the forming steps are represented. The used flat anvils had a width of $100 \mathrm{~mm}$. Between the forged areas of the ingot, not forged parts remained. In this way, it is possible to compare the microstructure of the ingot before and after hot-working. Out of the formed parts, samples for hot-tensile tests, as well as samples for light-microscopy examinations were cut. Also, from the non-forged areas samples for light-microscopy were worked out. Thus, a comparison of the microstructure before (cast microstructure with defects) and after forging as well as a comparison with the corresponding tensile tests is possible. As shown in the picture, the ingot was divided into eight parts (areas 1, 3, 5, 7 and 8 represent the initial state without deformation; sections 2, 4 and 6 are forged with different high reductions and local plastic strains). After comparison of the micrographs and tensile tests of all areas the samples were classified in "open", "partially closed" and "closed."
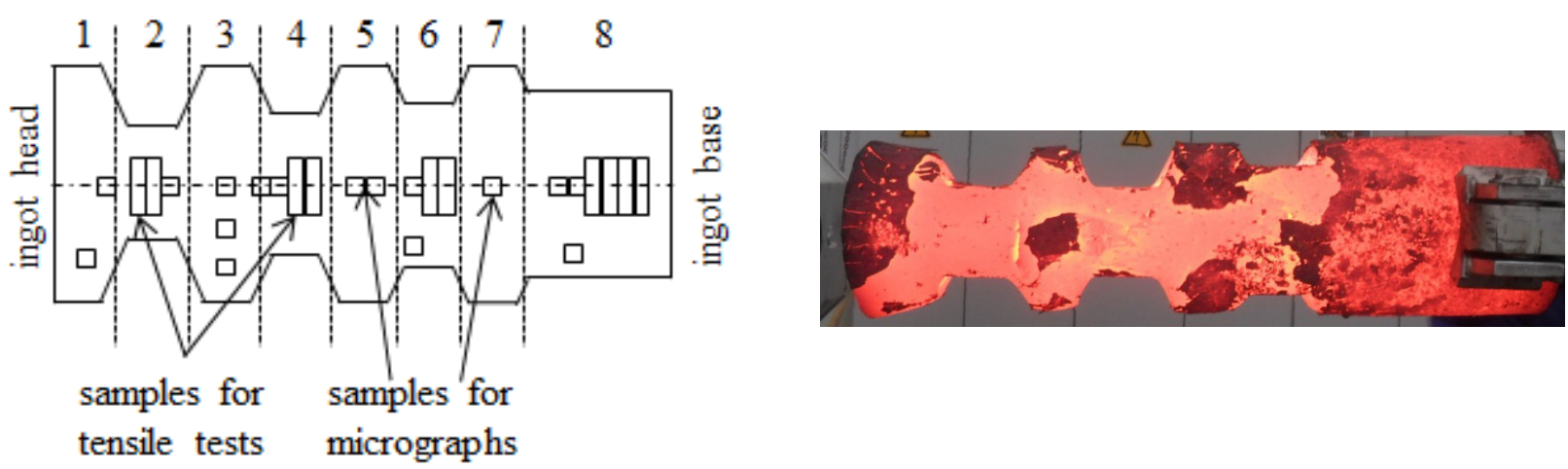

Fig. 6. Ingots on industrial scale with forged zones and sampling areas

\section{Numerical Examinations}

For the numerical simulation of the forging processes of the industrial ingots the software simufact.forming V14 was utilized by implementing the material-specific forming behavior. To analyze the closing process it was necessary to build up a multi-scale simulation. The macroscale was used for the material flow including temperature development of the whole ingot, the microscale for the forming behavior of the dendrites and their contact mechanism and the level between both to consider the cross section. 
At first, circular voids with various diameters in the center of the ingots were used to determine the necessary height reduction for closing. When the "contact status" takes the value "1" the pore is considered to be closed and the former opposite nodes are close together. In this way, a linear function for each material could be determined that describes the closing behavior. If the equivalent area of the void enlarges, the necessary height-reduction also becomes larger. Additionally, three other cavity shapes were also taken into account:

- elliptical shape with its largest extension along the forging direction

- "spongy zone," with a lot of single pores within a short distance

- "manifold void" geometry

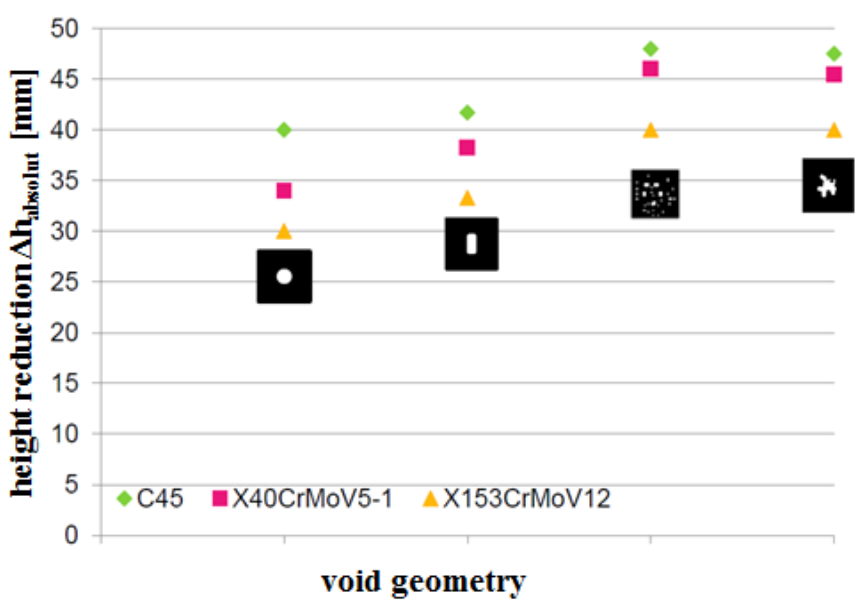

Fig. 7. Simulated correlation between reduction and geometry of defects for void closing

The simulation in Fig. 7 showed that for the closing of the elliptical shape a height reduction is needed, which is hardly larger than that for the circular shape. The reason is that the largest extension of the ellipse is reduced and the form becomes a circular-like shape during compression. The more complex forms "spongy zone" and "manifold pore" are more difficult to close.

Another numerical investigation concerned the shape of the anvils, which was changed from flatdies to v-shaped anvils with an angle of $135^{\circ}$. During simulation of compression tests of the circular shape it could be shown, that the necessary height reduction could be reduced over a third. The explanation for this is the more homogeneous and higher plastic strain in the core with vshaped anvils because the material is surrounded with the die and cannot bulge.

Also the dendritic surface structure of the inartificial cavities was taken into account in a separate microscopic model. It could be shown, that there is a concentration of stresses at the contact points of opposite dendrite arms. This phenomenon is beneficial for exceeding the critical plastic strain for an initiation of dynamically recrystallization. In preliminary compression tests it could be demonstrated, that the needed height-reduction for closing of natural pores is two times larger than that for artificial introduced drill holes. The reason is the rougher surface, which must be leveled.

As a result of the simulations and by help of a mathematical regression with the Avrami-equation as basis function, an equation for cavity closing of the industrial ingots was deduced, the so called closing function (1):

$$
h_{\text {reduction }}[\%]=0.21553 \cdot A_{\text {initial }}^{0.07138} \cdot P_{\text {anvil }}^{1} \cdot P_{\text {form }}^{0.5} \cdot P_{\sigma f}^{-0.14098} \cdot 2^{P_{\text {dendrites }}}
$$

This approach considers in form of separate coefficients the void size $\left(\mathrm{A}_{\text {initial }}\right)$, void shape $\left(\mathrm{P}_{\text {form }}\right)$, structure of the cavity surface $\left(\mathrm{P}_{\text {dendrites }}\right)$, anvil geometry $\left(\mathrm{P}_{\text {anvil }}\right)$ and the material parameter $\left(\mathrm{P}_{\text {of }}\right)$, which bases on the flow stress. The values of the coefficients can vary subjected to the individual process conditions (see table 2). By using this function, it is possible to calculate the necessary global height reduction for closing of the industrial forging ingots. 
Table 2. Values of coefficients of the closing function

\begin{tabular}{|l|ll|}
\hline Coefficient & \multicolumn{2}{|l|}{ Range } \\
\hline $\mathrm{P}_{\text {anvil }}$ & 1 & flat anvil \\
& 0.66 & V-shaped anvil with $135^{\circ}$ \\
\hline $\mathrm{P}_{\text {form }}$ & 1 & single pores, circular \\
& 1.5 & complex voids \\
\hline $\mathrm{P}_{\text {dendrites }}$ & 0 & $\begin{array}{l}\text { smooth surface } \\
\text { dendritic surface }\end{array}$ \\
\hline
\end{tabular}

In Fig. 8 a comparison of the experimental results and the calculated values out of the function for cavity closing and a function for closing circular, smooth pores is shown for the different ingot sections (see Fig. 6). Like described above, the results of the tensile tests of the forged ingots were divided into "open", "partially closed" and "closed". The volume fraction of closed cavities regards the achievable tensile strengths after forging. The classification "closed" means that over $85 \%$ of the tensile strength of defect-free material is reached, "partially closed" means under $85 \%$ up to $20 \%$ of the raw material is obtained and "open" means less than $20 \%$ of tensile strength. It can be seen, that the necessary height reduction for closing is calculated too low, if only ideal round pores are considered. When using the closing function that regards the void size, void form, structure of the cavity surface, anvil geometry and the material parameter a more realistic prediction can be made.

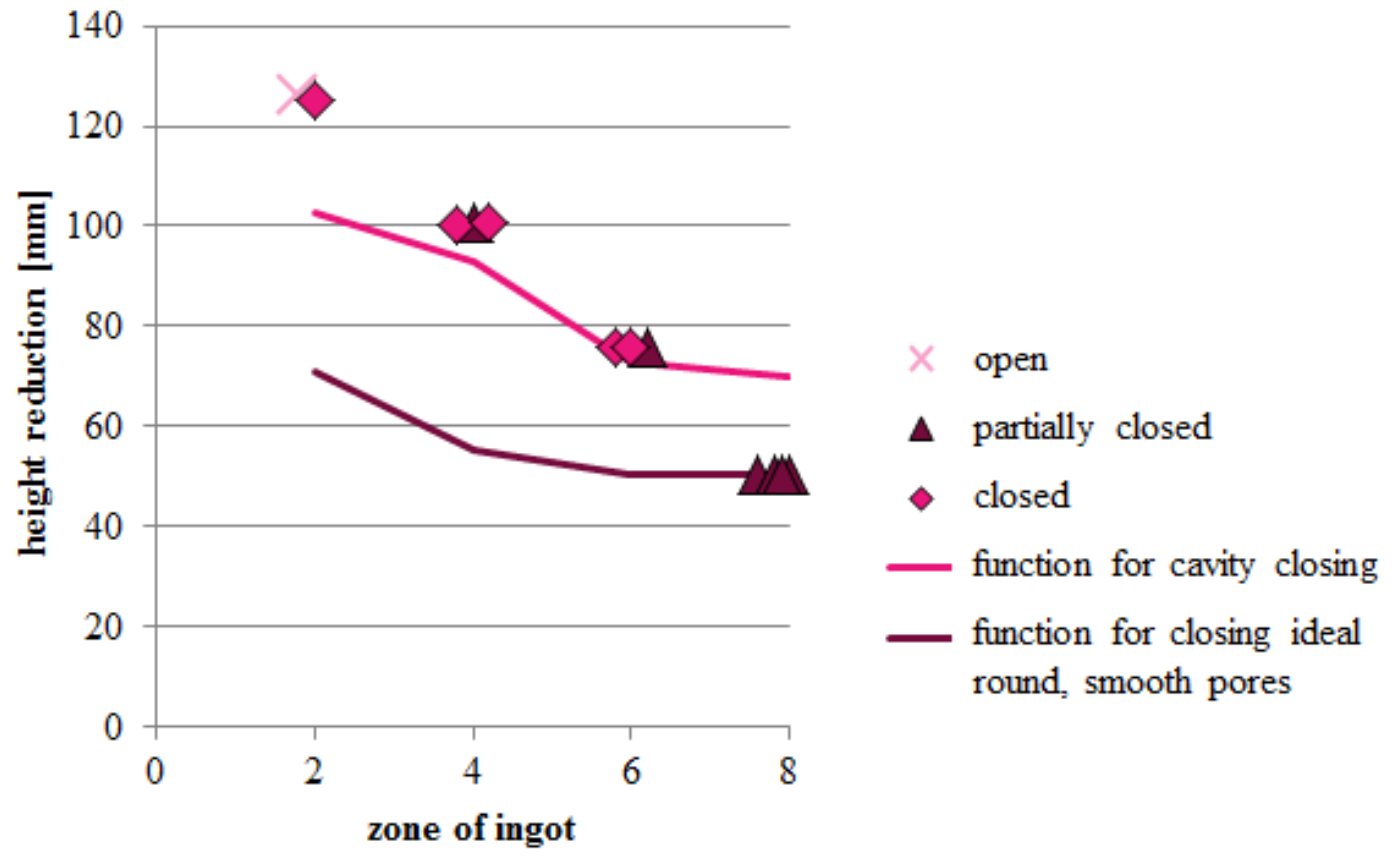

Fig. 8. Comparison of forging experiments and minimum calculated height reduction of steel grade X40CrMoV5-1

\section{Summary}

In large forging ingots, cavities with a dendritic surface can build up along the center line. Experimental investigation showed, that it is also possible to close such defects with a smaller height reduction on the microscopic scale, if the cavities do not come in contact to the atmosphere and if a plastic strain can be realized, that guarantees a meta-dynamically or statically recrystallization in the break time between the forging steps. These results were underlined by Gleeble compression tests.

Larger ingots were forged with different height reductions and afterwards hot tensile tests and metallographic analysis were performed. Because of the examinations, it was possible to divide the tested samples into "open", "partially closed" and "closed" with respect to the height reduction. 
These results were compared to the calculation made by help of a deduced equation for closing, which was the result of numerical simulation and a mathematically regression analysis for the three investigated materials.

The study gives hint that for a cavity closing on the microscopic scale a recrystallization with nucleation and grain growth is necessary. If the height reduction for closing of inartificial cavities is predicted in numerical simulations, the void size and the structure of the void surface must be considered to obtain reasonable results.

\section{References}

[1] P. Christiansen, J.H. Hattel, N. Bay, P.A. Martins, Physical Modeling and Numerical Simulation of V-Die Forging Ingot with Central Void, in: Proceedings of the Institution of Mechanical Engineers, Part C: Journal of Mechanical Engineering Science 228 (2014) 13, p. 2347-2356, doi: 10.1177/0954406213517878.

[2] D. Rosenstock, A. Melzner, G. Hirt, Analysis of Pore Closure in Open Die Forging by Experimental and Numerical Simulation: ICRF; 2nd International Conference; (2014), Milan.

[3] H. Kakimoto, T. Arikawa, Y. Takahashi, T. Tanaka, Y. Imaida, Developement of Forging Process Design to Close Internal Voids. In: Journal of Materials Processing Technology 210 (2010) 3, S. 415-22, doi: 10.1016/j.jmatprotec.2009.09.022.

[4] M.-S. Chen, Y.C. Lin, Numerical Simulation and Experimental Verifica-tion of Void Evolution inside Large Forgings during Hot Working, in: International Journal of Plasticity 49 (2013), p. 53-70, doi: 10.1016/j.ijplas.2013.02.017.

[5] K. Kittner, J. Wiesner, R. Kawalla, A New Approach for Void Closure in Bulk Metal Forming, in: Key Engineering Materials, 716 (2016), p. 595-604, doi: 10.4028/www.scientific.net/KEM.716.595

[6] M. Graf, M. Ullmann, R. Kawalla, Property-Oriented Production of Forged Magnesium Components, in: Materials Today: Proceedings 2S, (2015), p. 76-84, doi: 10.1016/j.matpr.2015.05.022

[7] F. Hoffmann, W. Jungnickel, G. Korpała, R. Kawalla, Die Bestimmung der Entfestigung mittels Offset-Methode und verfahrensbedingte Einflüsse auf das Ergebnis, in: Proceeding Meform (2011), Freiberg, p. $129-140$. 